\title{
A new reliable and rapid HPLC method for the simultaneous determination of amoxicillin and sulbactam pivoxil in pharmaceuticals. Application to both assay and dissolution samples
}

\author{
Mariela Fernanda RAZUC 1,2* (D), Fernanda Anabel CABRERA 3 (D), Mariano Enrique GARRIDO 1 (D), \\ María Verónica RAMIREZ-RIGO 2,3 (D)
}

1 INQUISUR, Universidad Nacional del SUR (UNS-CONICET), Av. Alem 1253, Bahía Blanca, Argentina.

2 Department of Biology, Biochemistry and Pharmacy, Universidad Nacional del SUR (UNS), San Juan 670, Bahía Blanca, Argentina.

3 PLAPIQUI, Universidad Nacional del SUR (UNS-CONICET), Camino La Carrindanga Km 7, Bahía Blanca, Argentina.

* Corresponding Author. E-mail: mariela.razuc@uns.edu.ar (M.F.R.); Tel. +54-291-575 5118.

Received: 19 July 2021 / Revised: 14 September 2021/ Accepted: 03 December 2021

\begin{abstract}
A fast, efficient and simple high performance liquid chromatographic method was developed and validated for the simultaneous determination of amoxicillin trihydrate (AMO) and sulbactam pivoxil (SP) in oral pharmaceutical dosage forms and, eventually, for their dissolution tests. The difference in molar absorptivities of these compounds constituted an analytical challenge, especially in formulations where AMO was in a higher proportion than SP. A reverse phase C18 column was used with a mobile phase consisting of acetonitrile and water (80:20 v/v) in isocratic mode. The retention times were found to be $2.26 \mathrm{~min}$ and $1.34 \mathrm{~min}$ for SP and AMO, respectively. The linearity range was evaluated over the concentration range of 2.5 and $250.0 \mu \mathrm{g} \mathrm{mL}-1$ (correlation coefficients higher than 0.9998 ). The method was validated according to the International Conference on Harmonization ICH guidelines regarding selectivity, linearity, accuracy, precision, limit of detection, limit of quantification, system suitability and robustness. The validated method was applied for the quantification of AMO and SP in commercial tablets and oral suspensions (AMO/SP ratio between 1:1 and 7:1), being the first method in the open literature that enables the correct quantification of both active ingredients in formulations with an AMO/SP ratio higher than 1:1. Also, the new method was successfully applied for the dissolution study of AMO/SP formulations, which was reported for the first time in the open literature. According to the obtained results, the proposed method can be applied in the quality control of pharmaceuticals containing a combination of amoxicillin and sulbactam pivoxil.
\end{abstract}

KEYWORDS: Amoxicillin trihydrate; sulbactam pivoxil; HPLC; method validation; dissolution; oral pharmaceutical dosage forms.

\section{INTRODUCTION}

Amoxicillin trihydrate (AMO), a broad-spectrum $\beta$-lactam antibiotic, is one of the most used antibiotics in the primary care setting [1]. However, $\beta$-lactam antibiotics are susceptible to be destroyed by $\beta$-lactamase enzymes. The continuous evolution and prevalence of these enzymes is the main cause of bacterial resistance [2]. A strategy to overcome this problem lies in using AMO combined with $\beta$-lactamase-inhibitors [3]. Sulbactam is an effective $\beta$-lactamase-inhibitor, but it has a poor absorption in the gastrointestinal tract. This problem was solved by the synthesis of the double ester prodrug, sulbactam pivoxil (SP). This prodrug is very well absorbed and, upon a rapid enzymatic hydrolysis, effectively delivers sulbactam in the serum [4]. The $\mathrm{AMO} / \mathrm{SP}$ combination is used in oral therapy (both solid oral forms and suspensions), and it is marketed in almost all the Latin American countries, Korea and China [5] in different AMO/SP ratios, ranging from 1:1 to $7: 1$.

The principal quality controls required for solid oral forms (capsules and tablets) and suspensions are the active pharmaceutical ingredient (API) determination and the corresponding dissolution test. In

How to cite this article: Razuc MF, Cabrera FA, Garrido ME, Ramirez-Rigo MV. New reliable and rapid HPLC method for the simultaneous determination of amoxicıllin and sulbactam pivoxil in pharmaceutıcals. Application to both assay and dissolution samples. J Res Pharm. 2022; 26(1): 123-135. 
accordance with official pharmacopeias, the API determinations must be carried out for both solid forms and suspensions; while the dissolution tests are only required for solid oral forms [6-8]. However, dissolution testing has been increasingly used to test suspensions in order to demonstrate bioequivalence and ensure product quality [9-11].

The combination of AMO and SP has not been referred to by any pharmacopoeia. In fact, there are no official analytical methods for SP. Different pharmacopeias report methods to quantify sulbactam sodium. However, these methods are not useful for sulbactam pivoxil due to the significant differences in solubility between the two drugs. On the other hand, methods for AMO analysis are reported in all pharmacopeias [68].

A comprehensive review of the literature has revealed that there are several articles proposing methods for the simultaneous determination of amoxicillin and sulbactam [12-16]. Nevertheless, only one of them studied the quantification of sulbactam in the SP prodrug form [16]. The authors developed a method based on high performance liquid chromatography (HPLC) with UV detection, which was proposed for dispersible tablets with a ratio of 1:1 AMO/SP. It is important to highlight that the molar absorptivities of these compounds are very different from each other, being much higher the one corresponding to AMO. This fact makes simultaneous HPLC/UV determination difficult when these APIs are found together in formulations where AMO is in a higher proportion than SP. In fact, as already mentioned, some commercial formulations have an AMO/SP ratio of 7:1. Thus, appropriate dilutions made to correctly quantify AMO (i.e., to avoid signal saturation) lead to very small chromatographic peaks for SP, and it is not possible to properly quantify it. This problem could also be present during the quantification of both analytes in dissolution tests (including 1:1 $\mathrm{AMO} / \mathrm{SP}$ ratio), due to their different aqueous solubility.

The goal of this research is to develop and validate a simple and fast HPLC method capable of simultaneously determining AMO and SP in solid oral forms and suspensions with AMO/SP ratios between 1:1 and 7:1. In addition, this work presents a dissolution study of formulations with these APIs, using the new method to determine both AMO and SP. To the best of our knowledge, there are no records in the open literature of such tests on AMO/SP formulations, nor of an analytical method which makes it possible their simultaneous determination in samples from dissolution tests. The method was able to perform the analysis in a shorter time, resulting in a reduction of both the amount of solvents needed and the generation of waste. On the other hand, a robustness study was also carried out in order to evaluate the reliability of the method during normal use.

\section{RESULTS AND DISCUSSION}

\subsection{Method development and optimization}

The simultaneous determination of AMO and SP presented two important challenges to be considered for the development of the analytical method. Firstly, both analytes have a very dissimilar solubility (i.e. SP has a much lower solubility in water than $\mathrm{AMO}$ ) and, on the other hand, they also differ considerably with respect to their molar absorptivities, as mentioned below (Figure 1). Accordingly, several mobile phases were initially tested.

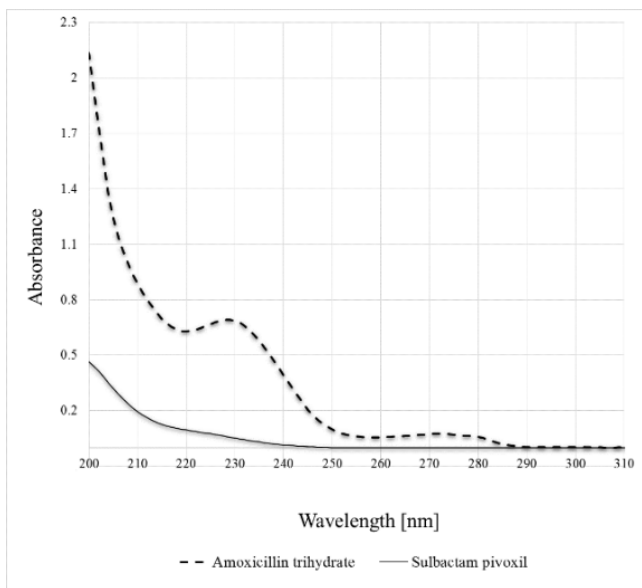

Figure 1. UV spectra of AMO (amoxicillin $0.025 \mathrm{mg} \mathrm{mL}^{-1}$, dotted line) and SP (sulbactam $0.025 \mathrm{mg} \mathrm{mL}^{-1}$, solid line) in acetonitrile/water (80:20). 
Various acetonitrile/water/methanol mixtures were evaluated, in accordance with other studies found in the literature [16]. However, low UV absorption bands for both AMO and SP were observed whenever methanol was present. In addition, the pressure in the system was higher when using methanol, which resulted in a lower separation efficiency and large peaks [17]. Moreover, acetonitrile has a lower cut-off than methanol, which is important because SP has its highest absorption at low wavelengths [18]. From the environmental point of view, both acetonitrile and methanol belong to class 2 of toxicity in the Guidance for Industry. Q3C-Tables and List [19]. However, acetonitrile is a stronger solvent than methanol, which would reduce the retention times of the analytes, as well as the waste produced in each run [20].

Based on these considerations, the combination of acetonitrile and water appeared to be a better option than the mobile phase using methanol. On the other hand, different pharmacopeias use ACN/aqueous solutions combination for the individual assays of amoxicillin trihydrate, amoxicillin sodium and sulbactam sodium [6,7]. In all cases, the percentage of acetonitrile used is between 2.5 [7] and $4 \% \mathrm{v} / \mathrm{v}$ [6]. However, under these conditions, only AMO could be correctly quantified, probably due to the low solubility of SP in those mobile phases.

Therefore, mobile phases with increasing acetonitrile percentages (20, 50, 70 and $80 \%)$ were tested. As expected, a higher percentage of acetonitrile made it possible to observe the SP peak and obtain lower retentions times. The SP peak could only be observed when the percentage of acetonitrile was higher than 50 $\%$. However, the mobile phase containing $50 \%$ of acetonitrile resulted in a broad and not well defined SP peak with a relatively long retention time $\left(\mathrm{R}_{\mathrm{t}}: 7.03 \mathrm{~min}\right)$. Better results were achieved when $80 \%$ of acetonitrile was used ( $R_{t}$ for SP: $2.26 \mathrm{~min}$ ). Using this mobile phase, well-defined peaks and low retention times were obtained, with total analysis times of $5 \mathrm{~min}$ for the determination of both analytes.

With the selected mobile phase, all the chromatographic parameters were optimized. The optimal operational conditions are shown in Table 1.

Table 1. Chromatographic conditions.

\begin{tabular}{ll}
\hline Column & $\begin{array}{l}\text { C18 } 4.6 \mathrm{~mm} \times 150 \mathrm{~mm}(5.0 \mu \mathrm{m} \\
\text { particle size })\end{array}$ \\
Flow rate $\left(\mathrm{mL} \mathrm{min}^{-1}\right)$ & 1 \\
Mobile phase & $\mathrm{ACN} /$ water $(80: 20 \% \mathrm{v} / \mathrm{v})$ \\
Injection volume $(\mu \mathrm{L})$ & 20 \\
Temperature $\left({ }^{\circ} \mathrm{C}\right)$ & 30 \\
Detection & \\
AMOX wavelength $(\mathbf{n m})$ & 273 \\
SULB wavelength $(\mathbf{n m})$ & 218 \\
Time for wavelength shift $(\mathbf{m i n})$ & 1.8 \\
\hline
\end{tabular}

The method was developed to be used in the quantification of both AMO and SP in tablets and suspensions, as well as in dissolution tests of such formulations. Two quantification strategies were tested. The first approach was to use a unique wavelength $(218 \mathrm{~nm})$ for the quantification of both active principles. It is important to note that the excipients normally present in the formulations had significant absorption bands at low wavelengths. Therefore, quantification of the APIs at the lower wavelengths was not possible, despite the fact that SP has a higher molar absorptivity in this region of the UV spectrum. Thus, $218 \mathrm{~nm}$ was the selected wavelength for the SP analysis. However, at this wavelength, differences in molar absorption between AMO and SP make their simultaneous determination difficult. This happens when the AMO/SP ratio is large, since adapting the sample preparation for a correct AMO quantification results in very small peak areas for $\mathrm{SP}$, leading to errors in integration. This is particularly the case when analyzing formulations with an AMO/SP ratio of 7:1, or if the method is applied for quantification during a dissolution test, mainly due to the low solubility of SP. For this reason, a second strategy was proposed, which used two different wavelengths for quantification: $218 \mathrm{~nm}$ for SP, and $273 \mathrm{~nm}$ for AMO. This approach enabled similar peak areas to be obtained for both active principles when they were in equal concentrations (Figure $2 \mathrm{~A}$ ). This method showed better results in the validation process, in terms of accuracy, precision and robustness. Therefore, it was selected as the optimal. 


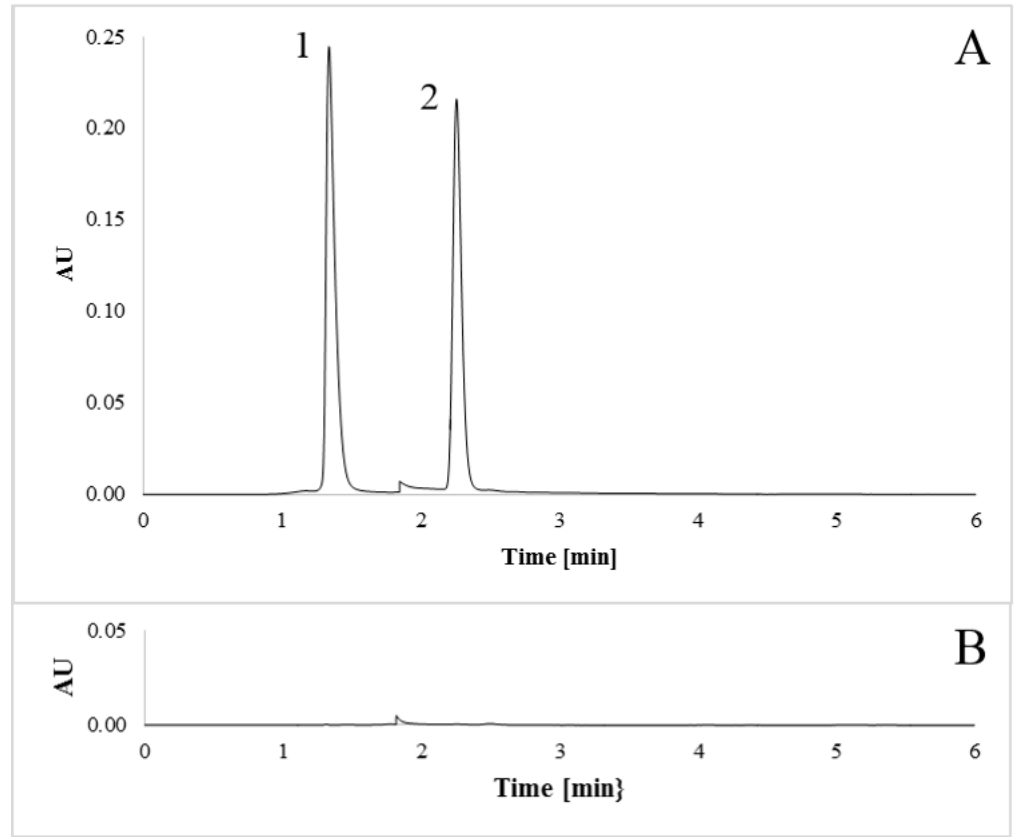

Figure 2. Chromatograms using the developed method. (A) 1: AMO (250 $\mu \mathrm{g} \mathrm{mL}^{-1}$ of amoxicillin) and 2: SP (250 $\mu \mathrm{g} \mathrm{mL}^{-1}$ of sulbactam). (B) Solution of excipients.

\subsection{Method validation}

As mentioned before, the chromatographic method was validated in accordance with the International Conference on Harmonization (ICH) guidelines Q2 (R1) [19]. The following parameters were evaluated: specificity, linearity, accuracy, precision, limit of detection (LOD), limit of quantification (LOQ), system suitability and robustness.

\subsubsection{Specificity}

Specificity was studied by analyzing solutions of the different excipients used in the formulations, prepared in the mobile phase, in order to corroborate that there were no chromatographic peaks due to matrix components at retention times close to those corresponding to AMO and SP. As it can be seen in Figure 2B, the chromatogram demonstrated the absence of interferences. In addition, AMO and SP could be properly quantified in the presence of excipients. The $t$ test, performed at three levels of concentration $(2.50,25.00$ and $\left.250.00 \mu \mathrm{g} \mathrm{mL}^{-1}\right)$, showed no significant differences between the concentrations obtained for both drugs with and without excipients. The $p$-value obtained for all comparisons performed was $>0.05$.

\subsubsection{Linearity and range}

The linearity of the method was evaluated by preparing and injecting standard solutions, whose concentrations ranged from 2.5 to $250 \mu \mathrm{g} \mathrm{mL}^{-1}$ for both AMO and SP. The calibration lines were constructed by regressing the peak area against the concentration of the standards, and showed that the method was linear over the entire study range for both APIs. Table 2 shows the parameters and linearity data of AMO and SP calibration curves (i.e. slope, standard error of slope, intercept, standard error of intercept and correlation coefficient). The correlation coefficients (R) values $>0.9998$ indicate that exits a high correlation between analyte peak area and concentration for both drugs. The Analysis of Variance (ANOVA) test showed that there was no lack of fit in any case, and that the linear model was appropriate to describe the behavior of the experimental data $(\alpha=0.05)$.

\subsubsection{Accuracy}

The method accuracy was evaluated by analyzing solutions which contained both AMO and SP at three concentration levels (low, medium and high), as well as the commonly used excipients.

The Federal Drug Administration of the United States (FDA) and the United States Pharmacopeia (USP) do not establish limits of acceptance for the accuracy [6,21]. However, it is well known that values close to 100 $\%$ of recovery are recommended. In our case, the percentage of recovery obtained for all concentrations and for both analytes ranged between 98.3-101.7 \% (Table 3). 
Table 2. Regression characteristics, LOD, LOQ and system suitability for the analysis of AMO and SP.

\begin{tabular}{|c|c|c|}
\hline & $\begin{array}{c}\text { SP } \\
(218 \mathrm{~nm})\end{array}$ & $\begin{array}{c}\text { AMO } \\
(273 \mathrm{~nm})\end{array}$ \\
\hline \multicolumn{3}{|l|}{ Regression date } \\
\hline Range concentration ( $\mu \mathrm{g} \mathrm{mL}-1)$ & $2.5-250$ & $2.5-250$ \\
\hline Slope & 3899.1 & 4223.4 \\
\hline Standard error of slope & 2.4 & 2.6 \\
\hline Intercept & 233.38 & -270.72 \\
\hline Standard error of intercept & 261.46 & 276.88 \\
\hline Correlation coefficient & 0.9999 & 0.9998 \\
\hline \multicolumn{3}{|l|}{ Limits } \\
\hline Detection limit ( $\left.\mu \mathrm{g} \mathrm{mL}^{-1}\right)$ & 0.6 & 0.6 \\
\hline Quantitation limit $\left(\mu \mathrm{g} \mathrm{mL}^{-1}\right)$ & 1.8 & 1.7 \\
\hline \multicolumn{3}{|l|}{ System suitability } \\
\hline Tailing factor, $T$ & 1.16 & 1.50 \\
\hline Resolution, Rs & \multicolumn{2}{|c|}{8.33} \\
\hline Theoretical plates, $\mathbf{N}$ & 5675 & 2172 \\
\hline System precision ( $\%$ RSD) & 0.51 & 0.33 \\
\hline Retention time (min) & 2.26 & 1.34 \\
\hline
\end{tabular}

Table 3. Determination of $\mathrm{AMO}$ and SP in laboratory prepared mixtures.

\begin{tabular}{|c|c|c|c|c|}
\hline \multirow[b]{2}{*}{$\begin{array}{l}\text { Concentration } \\
\left(\mu \mathrm{g} \mathrm{mL} \mathrm{L}^{-1}\right)\end{array}$} & \multicolumn{2}{|c|}{$\begin{array}{c}\text { SP } \\
(218 \mathrm{~nm})\end{array}$} & \multicolumn{2}{|c|}{$\begin{array}{c}\text { AMO } \\
(273 \mathrm{~nm})\end{array}$} \\
\hline & $\begin{array}{l}\text { Found* } \\
\left(\mu \mathrm{g} \mathrm{mL}{ }^{-1}\right)\end{array}$ & $\begin{array}{c}\text { Recovery } \\
(\%)\end{array}$ & $\begin{array}{l}\text { Found }^{*} \\
\left(\mu \mathrm{g} \mathrm{mL}^{-1}\right)\end{array}$ & $\begin{array}{c}\text { Recovery } \\
(\%)\end{array}$ \\
\hline 2.50 & 2.54 & 101.6 & 2.53 & 101.4 \\
\hline 25.00 & 25.10 & 100.4 & 24.58 & 98.3 \\
\hline 250.00 & 254.31 & 101.7 & 247.75 & 99.1 \\
\hline
\end{tabular}

* average of three determinations

\subsubsection{Precision}

Five and three concentration levels within the linear range were analyzed for repeatability and intermediate precision, respectively (Table 4). The results obtained from the repeatability study showed percentage relative standard deviation (\% RSD) values for both AMO and SP lower than $2 \%$ for all the concentrations under study, which were considered satisfactory.

Table 3 also shows the results of intermediate precision. In this case, the \% RSD values for AMO were in all cases below $2 \%$, as well. In comparison, the \% RSD values corresponding to SP were slightly above $2 \%$, with the highest value being $2.73 \%$.

The Spanish Association of Industry Pharmacists indicates that the maximal \% RSD depends on the range of acceptance [22]. In this sense, for a range of $90-110 \%$ and $n=3$ the maximum \% RSD should be $6.71 \%$. Therefore, according to these recommendations, the results obtained could be considered acceptable.

\subsubsection{Limit of detection and limit of quantification}

The LOD and LOQ were calculated based on Eq. 1 and Eq. 2. The values obtained for both AMO and $\mathrm{SP}$ are showed in Table 2. As it can be seen, the LOD was $0.6 \mu \mathrm{g} \mathrm{mL}-1$ for both analytes. On the other hand, the LOQ was calculated being 1.8 and $1.7 \mu \mathrm{g} \mathrm{mL}^{-1}$ for SP and AMO, respectively. The results obtained were slightly lower than the limits reported by Qi et al. (i.e. $\mathrm{AMO}-\mathrm{LOQ}=3.05 \mu \mathrm{g} \mathrm{mL}-1$; SP-LOQ $=4.03 \mu \mathrm{g} \mathrm{mL}^{-1}$ ) [16], which revealed that the proposed HPLC method was sensitive enough to determine AMO and SP. 
Table 4. Precision of the proposed HPLC method.

\begin{tabular}{|c|c|c|c|c|}
\hline \multirow[b]{2}{*}{$\begin{array}{l}\text { Concentration } \\
\left(\mu \mathrm{g} \mathrm{mL}^{-1}\right)\end{array}$} & \multicolumn{2}{|c|}{$\begin{array}{c}\text { SP } \\
(218 \mathrm{~nm})\end{array}$} & \multicolumn{2}{|c|}{$\begin{array}{c}\text { AMO } \\
(273 \mathrm{~nm})\end{array}$} \\
\hline & $\begin{array}{c}\text { Mean } \pm \text { SD } \\
\left(\mu \mathrm{g} \mathrm{mL}^{-1}\right)\end{array}$ & $\begin{array}{c}\text { RSD } \\
(\%)\end{array}$ & $\begin{array}{c}\text { Mean } \pm S D \\
\left(\mu g \mathrm{~mL}^{-1}\right)\end{array}$ & $\begin{array}{r}\text { RSD } \\
(\%)\end{array}$ \\
\hline \multicolumn{5}{|l|}{ Repeatability } \\
\hline 2.50 & $2.39 \pm 0.02$ & 0.74 & $2.53 \pm 0.04$ & 1.53 \\
\hline 6.25 & $6.25 \pm 0.06$ & 0.89 & $6.28 \pm 0.10$ & 1.67 \\
\hline 25.00 & $25.08 \pm 0.50$ & 1.98 & $24.87 \pm 0.25$ & 1.00 \\
\hline 125.00 & $125.41 \pm 1.12$ & 0.89 & $125.81 \pm 2.12$ & 1.69 \\
\hline 250.00 & $248.91 \pm 2.31$ & 0.93 & $258.26 \pm 1.93$ & 0.75 \\
\hline \multicolumn{5}{|l|}{$\begin{array}{l}\text { Intermediate } \\
\text { precision }\end{array}$} \\
\hline 6.25 & $6.18 \pm 0.17$ & 2.72 & $6.39 \pm 0.07$ & 1.17 \\
\hline 25.00 & $24.74 \pm 0.68$ & 2.73 & $24.88 \pm 0.20$ & 0.81 \\
\hline 125.00 & $127.09 \pm 3.47$ & 2.73 & $125.56 \pm 2.38$ & 1.89 \\
\hline
\end{tabular}

The mean and the $\%$ RSD were calculated considering $n=3$

\subsubsection{Suitability of the system}

The suitability parameters analyzed in this work were the tailing factor $(T)$, the resolution (Rs), the theoretical plates $(\mathrm{N})$, the system precision (evaluated as \% RSD) and the retention time $\left(\mathrm{R}_{\mathrm{t}}\right)$. These parameters were estimated in accordance with the USP [6]. The results obtained for both analytes are showed in Table 2.

The system precision indicates the performance of the chromatograph including the column, plumbing and environmental conditions. The highest $\%$ RSD obtained was $0.51 \%$ for SP. Values $\leq 1 \%$ are considered desirable [21].

The resolution indicates how well two peaks are separated. Well separated peaks are essential for a reliable quantitation. The value obtained for the developed method was 8.33. Values of Rs $>2$ are recommended [21].

The tailing factor affects the method accuracy. In this sense, when high $\mathrm{T}$ values are obtained, the integrator has difficulty in determining the peak ends, which affects the calculation of the area under the peaks. $\mathrm{T} \leq 2$ are considered desirable [21]. In the current study all values obtained were acceptable.

The theoretical plate number indicates the column efficiency. This parameter is related to the number of peaks that can be located per unit of chromatogram run time. $\mathrm{N}$ depends on the elution time, but in general it should be $>2000$. In this work, although the retention times are low, the $\mathrm{N}$ values were above 2000 for both APIs [21].

The retention times obtained were very short, being a run of 5 min enough to determine both $A M O$ and $\mathrm{SP}$. The $\mathrm{R}_{\mathrm{t}}$ obtained in the present work were $1.34 \mathrm{~min}$ for AMO and $2.26 \mathrm{~min}$ for SP. In this sense, the $\mathrm{R}_{\mathrm{t}}$ for both analytes were about three times lower than those previously reported, where the $R_{t}$ for AMO and SP were $3.4 \mathrm{~min}$ and $7.2 \mathrm{~min}$, respectively [16].

Moreover, the developed method is in agreement with the first and sixth of the 12 Principles of Green Chemistry [23]. The first principle says that it is better to prevent waste than to treat or clean up waste after it has been created. Thus, the shorter the chromatographic run, the lower the waste generated. On the other hand, the sixth principle is related to energy consumption, this principle states that energy requirements should be recognized for their environmental and economic impacts and should be minimized. The developed methods required less energy because the runs were shorter. In addition, the new method presented other advantages from the economical point of view. Therefore, the economic advantage was linked to the reduction of the total analysis time, which made it possible to use less solvents as well as to generate less waste, leading to a reduction in the costs of waste treatment. In addition, as it was previously mentioned, since the energy requirement of the analysis was reduced, this also resulted in economic savings. 


\subsubsection{Robustness}

The evaluation of the robustness of an analytical method is part of the validation requirements demanded by the regulatory authorities. This study is useful to know the factors that could negatively affect the quality of the results, as well as to transfer the developed methods. In this work, the robustness assessment was carried out by analyzing the changes in the following parameters: mobile phase composition (evaluated as acetonitrile percentage), flow rate of the mobile phase, temperature and wavelengths 1 and 2 . The analytical responses were the $\%$ recovery and the $\%$ RSD value for both analytes. The results obtained from the robustness analysis are summarized in Table 5.

The recoveries obtained upon the variation of the mentioned parameters were in the range of 97.1 - 101.8 $\%$ and $97.2-101.9 \%$ for SP and AMO, respectively. Furthermore, the \% RSD values for all determinations were below $1.6 \%$. As it can be seen, the flow rate was the parameter that had the greatest effect on the recoveries. The error in this parameter was the only one above $2 \%$. Although the error was less than $2.9 \%$, it would be important to have a strict control of this parameter during the analytical determinations. The results showed that slight variations in chromatographic conditions had a negligible effect on the response- Therefore, the method proved to be robust considering the parameters tested.

Table 5. Robustness analysis.

\begin{tabular}{|c|c|c|c|c|}
\hline \multirow[b]{2}{*}{ Chromatographic conditions } & \multicolumn{2}{|c|}{ SP } & \multicolumn{2}{|c|}{ AMO } \\
\hline & $\begin{array}{c}\text { Recovery } \\
(\%)\end{array}$ & $\begin{array}{c}\text { RSD } \\
(\%)\end{array}$ & $\begin{array}{c}\text { Recovery } \\
(\%)\end{array}$ & $\begin{array}{c}\text { RSD } \\
(\%)\end{array}$ \\
\hline Mobile phase (acetonitrile/water 78/22) & 99.9 & 0.9 & 98.6 & 0.4 \\
\hline Mobile phase (acetonitrile/water 82/18) & 100.8 & 0.9 & 99.1 & 0.4 \\
\hline Flow rate of mobile phase $0.98 \mathrm{~mL} \mathrm{~min}^{-1}$ & 101.8 & 0.5 & 101.9 & 0.2 \\
\hline Flow rate of mobile phase $1.02 \mathrm{~mL} \mathrm{~min}^{-1}$ & 97.1 & 0.3 & 97.2 & 1.2 \\
\hline Temperature $29.5^{\circ} \mathrm{C}$ & 99.9 & 0.8 & 98.6 & 0.1 \\
\hline Temperature $30.5^{\circ} \mathrm{C}$ & 100.9 & 1.2 & 101.1 & 0.7 \\
\hline Wavelength $217.5 \mathrm{~nm}$ & 101.3 & 1.0 & - & - \\
\hline Wavelength $218.5 \mathrm{~nm}$ & 99.2 & 1.1 & - & - \\
\hline Wavelength $272.5 \mathrm{~nm}$ & - & - & 98.5 & 1.6 \\
\hline Wavelength $273.5 \mathrm{~nm}$ & - & - & 101.9 & 1.3 \\
\hline
\end{tabular}

\subsection{Market samples analysis}

The applicability of the developed method was assessed by analyzing the AMO and SP content in commercially available pharmaceutical products. The corresponding results are showed in Table 6 . As it was previously mentioned, there is no information on the combination of AMO and SP in any pharmacopeia. However, AMO is coded in the USP, as well as in other pharmacopeias, both in tablets and suspensions. According to the USP, tablets and suspensions of AMO with clavulanate potassium (another $\beta$-lactamaseinhibitor) must contain the equivalent of not less than $90.0 \%$, and not more than $120.0 \%$ of the labeled amount of both APIs. This range is the same for tablets and suspensions of AMO [6]. Therefore, this range (90.0-120.0 $\%)$ was used for the commercial tablets and suspensions of AMO and SP analyzed in this work. As it can be seen in Table 6, the recovery \% for both AMO and SP in all the market samples analyzed are within the mentioned range. It is important to note that acceptable results were also obtained for tablets containing a 7:1 $\mathrm{AMO} / \mathrm{SP}$ ratio, which means that the developed method is able to be used in formulations with the highest $\mathrm{AMO} / \mathrm{SP}$ ratio present in market formulations.

\subsection{Application in dissolution tests}

The developed HPLC method was also used to analyze dissolution profiles of both AMO and SP in commercial tablets with a 7:1 AMO/SP ratio (Formulation B). A thorough review of the open literature and several pharmacopeias has revealed that there are no dissolution methods for this combination of APIs. Therefore, we started with the dissolution conditions proposed in the USP for the dissolution test of AMO tablets. These conditions are: $900 \mathrm{~mL}$ of water as the medium, an apparatus II at $75 \mathrm{rpm}$ and a temperature of $37 \pm 0.5^{\circ} \mathrm{C}$. Figure $3 \mathrm{~A}$ and $\mathrm{B}$ show the dissolution profiles of $\mathrm{AMO}$ and $\mathrm{SP}$ in the different media tested. As it 
can be seen, when water was used as the medium AMO (Figure 3A, blue circle), a percentage of dissolution close to $100 \%$ was achieved in $90 \mathrm{~min}$. On the other hand, despite the fact that the SP concentration in tablets was seven times lower than that of $\mathrm{AMO}$, the maximum dissolution percentage of SP was around $65 \%$ at 30 min, and remained constant until the end of the study (Figure 3B, blue circle). This may be because the saturation concentration was probably reached, due to the low water solubility of SP.

Table 6. Analysis of marketed formulations.

\begin{tabular}{lccc}
\hline $\begin{array}{l}\text { Commercial } \\
\text { formulation }\end{array}$ & AMO/SP ratio & Label value & $\begin{array}{c}\text { Recovery } \\
\text { (\%) }\end{array}$ \\
\hline $\begin{array}{l}\text { Formulation A, tablets } \\
\text { AMO (as amoxicillin trihydrate) }\end{array}$ & $1: 1$ & $250 \mathrm{mg} / \mathrm{tablet}$ & 95.5 \\
$\quad \begin{array}{l}\text { SP (as sulbactam pivoxil) } \\
\text { Formulation B, tablets }\end{array}$ & & $250 \mathrm{mg} / \mathrm{tablet}$ & 97.6 \\
$\quad \begin{array}{l}\text { AMO (as amoxicillin trihydrate) } \\
\text { SP (as sulbactam pivoxil) }\end{array}$ & $7: 1$ & $875 \mathrm{mg} / \mathrm{tablet}$ & 91.2 \\
$\begin{array}{l}\text { Formulation C, suspension } \\
\text { AMO (as amoxicillin trihydrate) }\end{array}$ & & $125 \mathrm{mg} / \mathrm{tablet}$ & 93.4 \\
$\quad$ SP (as sulbactam pivoxil) & $1: 1$ & & \\
\hline $\mathbf{n = 6}$ & & $250 \mathrm{mg} / 5 \mathrm{~mL}$ & 98.7 \\
\end{tabular}

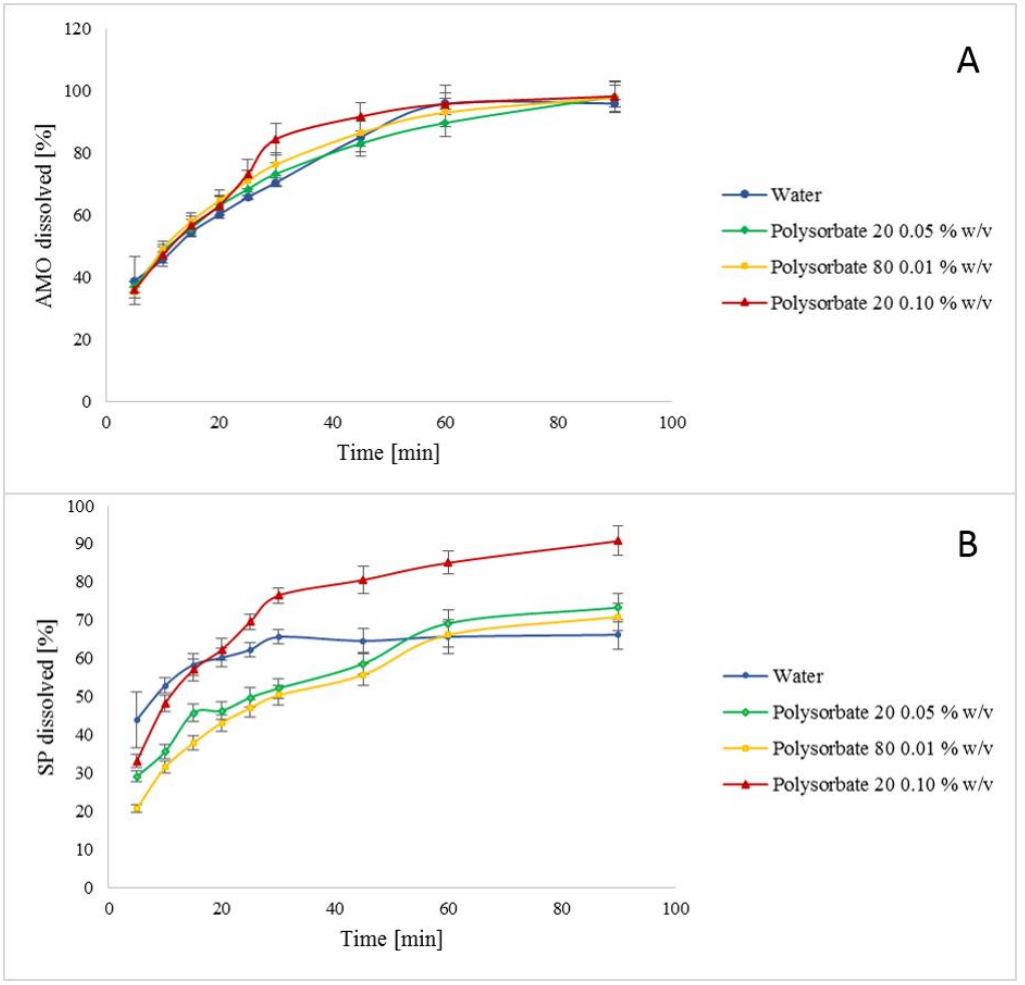

Figure 3. Dissolution profiles of tablets of formulation B (labeled amounts, AMO $875 \mathrm{mg}$ and SP $125 \mathrm{mg}$ ). A: profiles of AMO and B: profiles of SP. Dissolution medium water (blue circle), polysorbate $200.05 \% \mathrm{w} / \mathrm{v}$ (green rhombus), polysorbate $800.01 \% \mathrm{w} / \mathrm{v}$ (yellow square) and polysorbate $200.10 \% \mathrm{w} / \mathrm{v}$ (red triangle).

SP remains as a prodrug during its passage through the gastrointestinal tract. After absorption, SP is hydrolyzed, releasing the sulbactam into the serum [4]. It is likely that, due to the low water solubility of SP, bile salts play an important role in its solubilization in the gastrointestinal tract. Therefore, the effect of adding several surfactants to the dissolution medium was tested. The surfactants investigated were sodium lauryl sulfate, polysorbate 20 and polysorbate 80 . Prior to the dissolution tests, preliminary HPLC assays were carried out to investigate whether the added surfactant could interfere with the determination of both analytes. It is noteworthy that the use of polysorbates (both 20 and 80) did not cause distortion in the chromatographic 
peaks of the APIs, and therefore, they could be determined accurately. However, as this did not occur with sodium lauryl sulfate, AMO and SP could not be correctly quantified using this surfactant.

The critical micellar concentration (CMC) of polysorbate 20 and polysorbate 80 are $0.06 \mathrm{mM}$ and 0.012 $\mathrm{mM}$, respectively [24]. Initially, the concentrations used were about seven times their $\mathrm{CMC}$, being 0.05 gr \% $\mathrm{w} / \mathrm{v}$ (Figure 3, green rhombus) and $0.01 \mathrm{gr} \% \mathrm{w} / \mathrm{v}$ (Figure 3, yellow square) for polysorbate 20 and 80, respectively [25]. As it can be seen in Figure 3, both media have similar effects. In both cases, the dissolution profiles showed lower dissolution percentages than those observed in water at the beginning of the test, while these percentages were higher than those in water at the end of the tests. In spite of the similarity between polysorbates 20 and 80, SP showed higher dissolution percentages using polysorbate 20. Therefore, this surfactant was used at a higher concentration in the following experiments. The dissolution profiles of AMO and SP in polysorbate 20 at 0.10 gr \% w/v are showed in Figures $3 \mathrm{~A}$ and $3 \mathrm{~B}$ (red triangle), respectively. Although the percentage of dissolved $\mathrm{AMO}$ at $90 \mathrm{~min}$ is almost equal using either medium, in polysorbate 20 at $0.10 \mathrm{gr} \% \mathrm{w} / \mathrm{v}$ AMO reached higher values at shorter times. On the other hand, when this medium was used, the SP dissolution profile improved notoriously. In this case, the maximum dissolved percentage achieved was around $91 \%$ at $90 \mathrm{~min}$, which was much higher than using water as the medium (i.e. $66 \%$ at 90 $\min )$.

Therefore, polysorbate 20 at $0.10 \mathrm{gr} \% \mathrm{w} / \mathrm{v}$ was the best of the media tested in this study, and was able to significantly improve the dissolution profiles of both AMO and SP. In addition, it was demonstrated that this surfactant did not cause interferences when analyzing the dissolution with the proposed method. This study is the first in literature related to the dissolution test of the combination of AMO and SP. Such test needs to be optimized and validated. However, the study performed serves as a beginning for the development of future dissolution methods.

\section{CONCLUSION}

A fast, simple and sensitive isocratic reverse phase HPLC method was developed for the simultaneous determination of amoxicillin trihydrate and sulbactam pivoxil in both pharmaceutical formulations and dissolution tests. No interferences were found with excipients commonly used in oral suspensions and tablets. Well resolved chromatographic peaks were obtained in shorter analysis times. Both analytes could be determined in less than five minutes, which provided some economic advantages, and a low generation of residues. Moreover, the method proved to be reliable, meeting the requirements for linearity, precision, accuracy, robustness, limit of detection, limit of quantification and system suitability in the range of 2.5-250 $\mu \mathrm{g} \mathrm{mL} \mathrm{m}^{-1}$.

The developed method was found suitable for determining AMO and SP in tablets and oral suspensions, even in formulations where the AMO/SP ratio was as high as 7:1. This is the first analytical method that has been demonstrated to be able to determine both APIs in AMO/SP ratios higher than 1:1. In addition, a dissolution test for tablets containing AMO and SP was carried out for the first time, and the proposed method was successfully used to obtain the corresponding dissolution profiles. Even though the dissolution test needs to be optimized and validated, this study represents a start for the proposal of a valid dissolution method for the study of this type of formulations.

\section{MATERIALS AND METHODS}

\subsection{Chemicals and reagents}

Amoxicillin was purchased from ANMAT (Buenos Aires, Argentina). Sulbactam pivoxil (SP) was obtained from Kalung Group Ltd. (Hong Kong, China). The excipients used were: citric acid, sodium benzoate, sucrose, carboxymethylcellulose and strawberry flavor. Sucrose was obtained from Ledesma (Buenos Aires, Argentina), and the other excipients were purchased from Saporiti (Buenos Aires, Argentina). In addition, polysorbate 20 (Cicarelli, San Lorenzo, Argentina), polysorbate 80 (Saporiti, Buenos Aires, Argentina) and sodium lauryl sulfate (Cicarelli, San Lorenzo, Argentina) were used in the dissolution tests.

On the other hand, the mobile phase was prepared using ultrapure water supplied by Bernardo Lew (Buenos Aires, Argentina), acetonitrile (UHPLC quality) obtained from PanReac Applichem (Barcelona, Spain), and methanol (U.V.E Buenos Aires, Argentina). All solutions were filtered through $0.45 \mu \mathrm{m}$ pore size hydrophilic polyvinylidene fluoride (PVDF) membrane filters (Durapore, Darmstadt, Germany), and degassed in an ultrasonic bath. 
Three formulations of the Argentine market were tested, two of them in tablets (formulation A and B), and one in suspension (formulation C). The label values of amoxicillin and sulbactam in these formulations are the following: formulation A, $250 \mathrm{mg}$ of $\mathrm{AMO}$ and $\mathrm{SP} /$ tablet; formulation B, $875 \mathrm{mg}$ of $\mathrm{AMO}$ and $125 \mathrm{mg}$ of SP/ tablet; and formulation C, $250 \mathrm{mg}$ of $\mathrm{AMO}$ and $\mathrm{SP} / 5 \mathrm{~mL}$ of suspensions.

\subsection{Instrumentation}

The UV absorption spectra were recorded in a T60 UV-Visible spectrophotometer, PG Instruments (Lutterworth, UK). A Cole Palmer 8892 ultrasonic bath (Vernon Hills, USA) was used to assist in the preparation of samples and solutions.

A Waters Alliance e2695 HPLC system (Milford, USA), equipped with a Waters 2998 diode array detector (Milford, USA), and a thermostatized column compartment was used for method development and validation.

The dissolution study was assessed using a dissolution apparatus II (708-DS, Dissolution Apparatus, Agilent Technologies) with auto-sampling (Agilent 8000, Dissolution Sampling Station, Agilent Technologies).

\subsection{Stock, working and standard calibration solutions}

AMO and SP stock solutions of $0.25 \mathrm{mg} \mathrm{mL}^{-1}$ were prepared by weighing the appropriate amounts of each drug and dissolving them with the mobile phase, i.e. acetonitrile/water (80:20, v/v). The dissolution process was aided with the application of ultrasound. Working standard solutions were obtained by appropriate dilution of the stock solutions with the mobile phase. Standard calibration solutions were prepared by appropriate dilutions of working standard solutions in the mobile phase in the range between 2.5 and $250.0 \mu \mathrm{g} \mathrm{mL}-1$ for both $\mathrm{AMO}$ and SP.

\subsection{Chromatographic separation procedure}

Chromatographic separation was carried out using a $4.6 \mathrm{~mm} \times 150 \mathrm{~mm}$ Phenomex Gemini C18 column, with a particle size of $5.0 \mu \mathrm{m}$ (Torrance, USA). Also, a C18 Phenomenex Gemini pre-column was used. The column was thermostatized at $30^{\circ} \mathrm{C}$. The elution was performed in isocratic mode using acetonitrile/water $(80: 20, \mathrm{v} / \mathrm{v})$ as the mobile phase. The flow rate and the injection volume were set at $1 \mathrm{~mL} \mathrm{~min}-1$ and $20 \mu \mathrm{L}$, respectively. The method used two wavelengths for the determination: $218 \mathrm{~nm}$ for SP and $273 \mathrm{~nm}$ for AMO. All method parameters were optimized in a univariate way (i.e. varying one factor at a time). The optimal conditions were selected taking into account the retention times, peak resolution and sensitivity.

\subsection{Method validation}

The optimized method was validated in accordance with the International Conference of Harmonisation (ICH) guidelines Q2 (R1) [19]. Therefore, selectivity, linearity, accuracy, precision, limit of detection, limit of quantification, system suitability and robustness were evaluated.

\subsubsection{Specificity}

To evaluate the method specificity, different solutions were prepared using a mixture of acetonitrile: water $(80: 20 \mathrm{v} / \mathrm{v})$ as solvent: a) standard solutions of AMO and SP $(250 \mu \mathrm{g} / \mathrm{mL}$ as amoxicillin and sulbactam), prepared as indicated in section $4.3, \mathrm{~b}$ ) a solution of the excipients commonly used in the pharmaceutical formulations, and c) standard solutions of AMO and SP together with the commonly used excipients. The excipients used were: citric acid, sodium benzoate, sucrose, carboxymethylcellulose and strawberry flavor. All solutions were prepared in triplicate. The objective was to evaluate the presence of chromatographic peaks corresponding to possible interferences in the vicinity of the retention times of the analytes. In addition, in order to verify if the quantification of both $\mathrm{AMO}$ and SP was correctly performed even in the presence of excipients, a $t$-test was carried out to compare the concentrations recovered for solutions a and c.

\subsubsection{Linearity and range}

For the linearity evaluation, seven concentration levels in the range between 2.5 and $250.0 \mu \mathrm{g} \mathrm{mL}^{-1}$ were studied for AMO and SP. Thus, standard solutions of concentrations 2.50, 6.25, 12.50, 25.00, 50.00, 125.00 and $250.00 \mu \mathrm{g} \mathrm{mL}^{-1}$ of each drug were prepared in quadruplicate. The peak areas obtained were plotted versus the analyte concentrations, and the corresponding straight line equation was estimated by ordinary least squares. The linearity of both calibration curves was assessed by inspection of the corresponding correlation coefficient (R). Also, the lack of fit statistical test was performed by Analysis of Variance (ANOVA) [26]. All the calculations were performed using the ULC 2.0 software [27]. 


\subsubsection{Accuracy}

Accuracy was evaluated by recovery studies. For this purpose, standard solutions with known concentrations of both drugs and appropriate amounts of excipients were prepared to have a composition similar to that of the formulation. The solutions were prepared using the mobile phase as a solvent, as explained in section 4.3. Three concentration levels were analyzed within the studied linear range: the low level had a concentration of $2.5 \mu \mathrm{g} \mathrm{mL}^{-1}$, the medium level $25.0 \mu \mathrm{g} \mathrm{mL}^{-1}$, and the high concentration was 250.0 $\mu \mathrm{g} \mathrm{mL} \mathrm{m}^{-1}$. The assay was conducted in triplicate, and the percentage recoveries were calculated for both drugs following the ICH guidelines [19].

\subsubsection{Precision}

Precision was evaluated in terms of both repeatability and intermediate precision. Precision was reported as the percentage relative standard deviation (\% RSD), and it was calculated for each one of the concentration levels studied in the recovery experiments $(n=3)$ for both AMO and SP. The intermediate precision was calculated in different days for three of the concentration levels $\left(6.25,25.00\right.$ and $125.00 \mu \mathrm{g} \mathrm{mL}^{-1}$; $n=3)$.

\subsubsection{Limit of detection and limit of quantification}

The determination of the limit of detection (LOD) and the limit of quantification (LOQ) for both AMO and SP were calculated using the following equations according to $\mathrm{ICH}$ guidelines [9]:

$$
\begin{aligned}
& \mathrm{LOD}=(3.3 \times \mathrm{Q}) / \mathrm{S} \\
& \mathrm{LOQ}=(10 \times \mathrm{Q}) / \mathrm{S}
\end{aligned}
$$

Where $Q$ is the standard deviation of the intercept and $S$ the slope of the calibration curve.

\subsubsection{System suitability}

System suitability was checked by calculating the tailing factor $(\mathrm{T})$, the number of theoretical plates $(\mathrm{N})$, the resolution (Rs), the retention time $\left(R_{t}\right)$ and the system precision. These parameters were evaluated by injecting a standard solution of AMO and SP of $250 \mu \mathrm{g} \mathrm{mL}^{-1}$ six times.

\subsubsection{Robustness}

Robustness of the system was assessed by analyzing the effect of small variations in some operational variables on the recovery percentage. The studied parameters were: composition of the mobile phase (evaluated as the variation of the percentage of acetonitrile), flow rate, temperature, wavelength 1 and wavelength 2. The variables, as well as the corresponding studied interval, are shown in Table 7. All measurements were obtained by injecting a $250 \mu \mathrm{g} \mathrm{mL}^{-1}$ standard solution of AMO and SP. The study was carried out in a univariate manner, and was performed in triplicate.

Table 7. Variables used in the experimental design of robustness.

\begin{tabular}{llccc}
\hline & Factors & Low (-) & High (+) & Units \\
\hline A & Acetonitrile & 78 & 82 & $\%$ \\
B & Flow rate & 0.98 & 1.02 & $\mathrm{~mL} \mathrm{~min}^{-1}$ \\
C & Temperature & 29.5 & 30.5 & ${ }^{\circ} \mathrm{C}$ \\
D & Wavelength 1 & 272.5 & 273.5 & $\mathrm{~nm}$ \\
E & Wavelength 2 & 217.5 & 218.5 & $\mathrm{~nm}$ \\
\hline
\end{tabular}

\subsection{Preparation of sample solutions}

The procedure followed to prepare the sample solutions for tablets formulation was the following: five tablets of each commercial formulation were accurately weighed and powdered. The average tablet weight was calculated and registered. A quantity of powder, equivalent to about $80 \mathrm{mg}$, was accurately weighed and transferred into a $50 \mathrm{~mL}$ volumetric flask. The powder was diluted in the mobile phase and sonicated until complete dissolution of the APIs. Then, appropriate dilutions of these solutions were carried out with the mobile phase in $10 \mathrm{~mL}$ volumetric flasks. 
The commercial suspension was reconstituted with a given volume of tap water according to the instructions on the label. Then, $0.25 \mathrm{~mL}$ of the suspension was transferred to a $50 \mathrm{~mL}$ volumetric flask. The solution was made with the mobile phase, and sonication was used to assist the total dissolution of the APIs. Then, $1 \mathrm{~mL}$ of this solution was diluted with the mobile phase in a $10 \mathrm{~mL}$ volumetric flask.

All the solutions obtained were filtered previous to their injection in the HPLC instrument.

\subsection{Dissolution tests}

The developed method was also applied for the APIs quantification in the dissolution tests of tablets of the formulation B. The selected dissolution conditions used were the ones proposed for the United States Pharmacopeia (USP) for the dissolution test of amoxicillin tablets. In this sense, the dissolution was carried out using a USP apparatus-II (Paddle) at $37 \pm 0.5^{\circ} \mathrm{C}$ in $900 \mathrm{~mL}$ of water $75 \mathrm{rpm}$ [6]. In addition, several media containing polysorbate $20(0.05$ and $0.10 \% \mathrm{w} / \mathrm{v})$ and polysorbate $80(0.01 \% \mathrm{w} / \mathrm{v})$ were tested. Samples were withdrawn from the dissolution media at intervals of 5, 10, 15, 20,25, 30, 45, 60 and $90 \mathrm{~min}$. Then, $1.00 \mathrm{~mL}$ of each sample was diluted in a $5 \mathrm{~mL}$ volumetric flask with acetonitrile. The solutions obtained were filtered and analyzed using the proposed method. All the analyses were carried out in triplicate.

Acknowledgements: Secretaría de Políticas Universitarias (Ministerio de Educación, Argentina) (Res. SPU 1793/14), Universidad Nacional del Sur (PGI 24/Q086, PGI 24/B252), Consejo Nacional de Investigaciones Científicas y Técnicas (CONICET, PIP 11220150100704CO), and Agencia Nacional de Promoción Científica y Tecnológica (ANPCyT, PICT 201-0659, PICT-2018-00735) support this study. The authors also would thank to T. Odoux and F. Delucchi (PLAPIQUI), M. Murrie (Ministerio de Salud de la Provincia de Buenos Aires, Argentina) and Subsecretaría de Vinculación Tecnológica (UNS) for their technical assistance.

Author contributions: Concept - M.F.R, M.V.R.R; Design - M.F.R., F.A.C., M.V.R.R.; Supervision - M.V.R.R., M.E.G.; Resources - M.V.R.R., M.E.G.; Materials - M.V.R.R.; Data Collection and/or Processing - M.F.R, F.A.C.; Analysis and/or Interpretation - M.F.R.; Literature Search - M.F.R.; Writing - M.F.R.; Critical Reviews - M.F.R, F.A.C., M.E.G, M.V.R.R.

Conflict of interest statement: The authors declared no conflict of interest.

\section{REFERENCES}

[1] WHO, Model List of Mssential

https://www.who.int/publications/i/item/WHOMVPEMPIAU2019.06. (Accessed on 14 July 2021).

[2] Miller L, Ratnam K, Payne D. $\beta$-Lactamase-inhibitor combinations in the 21st century: current agents and new developments. Curr Opin Pharmacol. 2001; 1(5): 451-458. [CrossRef]

[3] Drawz S and Bonomo R. Three decades of $\beta$-lactamase inhibitors. Clin Microbiol Rev. 2010; 23(1): 160-201. [CrossRef]

[4] English R, Girard D, Jasys V, Martingano R, Kellogg M. Orally effective acid prodrugs of the $\beta$-lactamase inhibitor sulbactam. J Med Chem. 1990; 33(1): 344-347. [CrossRef]

[5] Soutric J, Bantar C, Caruso N, Heguilén R, Casellas J, Casellas J, Farinati A, Jasovich A, Arenoso H, Rodriguez M. Review of pharmacokinetic, pharmacodynamic and clinical studies with a modern combination of amoxicillin/sulbactam. Chemotherapy. 2006; 52(4): 200-204. [CrossRef]

[6] USP, United States of Pharmacopeia in USP30-NF25, The United States Pharmacoepial Convention. 2007.

[7] EP, European Pharmacopoeia 5th Ed., 2005.

[8] FNA, Farmacopea Nacional Argentina F.N.A. 7th Ed., 2003.

[9] Gao Z and Westenberger B. Dissolution testing of acetaminophen suspension using dialysis adapter in flow-through apparatus: a technical note. AAPS Pharm Sci Tech. 2012; 13: 944-948. [CrossRef]

[10] Rivera-Leyva J, García-Flores M, Valladares-Méndez A, Orozco-Castellanos L, Martínez-Alfaro M. Comparative studies on the dissolution profiles of oral ibuprofen suspension and commercial tablets using biopharmaceutical classification system criteria. Indian J Pharm Sci. 2012; 74(4): 312-318.

[11] Machado Rubim A, Bandeira Rubenick J, Varini Laporta L, Bueno Rolim C. Development and validation of a dissolution method using HPLC for diclofenac potassium in oral suspension. Braz J Pharm Sci. 2014; 50(2): 423-429. [CrossRef] 
[12] Anusha N, Uday Kamath B. Simultaneous estimation of amoxicillin and sulbactam in a parenteral formulation by reverse phase HPLC method. Int J Pharm Pharm. Sci. 2012; 4(4): 330-336.

[13] Chandana P, Srinivas N, Tuljarani G. Development and validation of RP-HPLC method for simultaneous estimation of amoxycillin and sulbactam in binary mixture. Int J Pharma Res Rev. 2015; 5(1): 47-52.

[14] Pei Q, Yang G, Li Z, Peng X, Fan J, Liu Z. Simultaneous analysis of amoxicillin and sulbactam in human plasma by HPLC-DAD for assessment of bioequivalence. Journal of Chromatography B. 2011; 879(21): 2000-2004. [CrossRef]

[15] Wang P, Qi M, Sun Y, Yang J. A liquid chromatographic method for simultaneous determination of amoxicillin sodium and sulbactam sodium in a combination formulation. J Pharm Biomed Anal. 2004; 36(3): 565-569. [CrossRef]

[16] Qi M, Wang P, Sun Y, Wang J. An LC method for simultaneous determination of amoxicillin and sulbactam pivoxil in a combination formulation. J Liq Chrom Relat Tech. 2003; 26(12): 1927-1936. [CrossRef]

[17] Aburjai T, Alzweiri M, Al-Hiari Y. Temperature and pressure behaviours of methanol, acetonitrile/water mixtures on chromatographic systems. Am J Chem. 2011; 2(8): 934-937.

[18] Safaei Z, Bocian S, Buszewski B. Green chromatography-carbon footprint of columns packed with core-shell materials. RSC Advances. 2004; 4(96): 53915-53920. [CrossRef]

[19] ICH, ICH Topic Q2 (R1) Validation of Analytical Procedures: Text and Methodology, International Conference Harmonization of Technical Requirements for Registration of Pharmaceuticals for Human Use 2005.

[20] Yufera, E, Química orgánica básica y aplicada: de la molécula a la industria, Reverte, Barcelona, Spain 1993.

[21] FDA, U.S. Food and Drug Administration. Reviewer guidance, validation of chromatographic methods. 1994. https://www.fda.gov/regulatory-information/search-fda-guidance-documents/reviewer-guidance-validationchromatographic-methods. (Accessed on 14 July 2021).

[22] Aguirre Ortega L. et al. Validación de métodos analíticos. AEFI, Asociación Española de Farmacéuticos de la Industria, Spain, 2001.

[23] Anastas P, Kirchhoff M. Origins, current status, and future challenges of green chemistry. Acc Chem Res. 2002; 35(9): 686-694. [CrossRef]

[24] Fotaki N, Brown W, Kochling J, Chokshi H, Miao H, Tang K, Gray V. Rationale for selection of dissolution media: three case studies. Dissolution Technologies 2013; 20(3): 6-13. [CrossRef]

[25] Niazi S, Handbook of Pharmaceutical Manufacturing Formulations, third ed., CRC Press, Deerfield, Illinois, USA 2000.

[26] Massart DL, Vandeginste BGM, Buydens LMC, De Jong S, Lewi PJ, \& Smeyers-Verbeke J, Handbook of Chemometrics and Qualimetrics: Part A: Elservier Science B, Amsterdam, The Netherlands 1997.

[27] ULC 2.0 software, O. Huguet Ibars and R. Boqué Martí, Universitat Rovira i Virgili, Tarragona, Spain 2006.

This is an open access article which is publicly available on our journal's website under Institutional Repository at http://dspace.marmara.edu.tr. 